\title{
POLÍTICAS PÚBLICAS PARA A VÍTIMA: AÇÕES DO CNJ E CNMP EM FACE DA AGENDA ODS 2030
}

PUBLIC POLICIES FOR THE VICTIM: CNJ AND CNMP' INITIATIVES CONSIDERING THE UNITED NATIONS' 2030 AGENDA

\section{Antonio Henrique Graciano Suxberger ${ }^{1}$ \\ UniCEUB - DF \\ Henrique Bawden Silverio de Castro ${ }^{2}$ \\ LAPIN - DF}

Resumo

O artigo analisa a conformação normativa das políticas públicas dirigidas às vítimas de crimes pelos agentes estatais participantes do sistema judicial-penal. Seguidamente, compara essa estruturação com o Objetivo 16, referente à "Paz,

${ }^{1}$ Doutor (Universidade Pablo de Olavide, Sevilha, Espanha, 2009), Mestre em Direito (Universidade de Brasília, 2005), Especialista (Ordem Jurídica e Ministério Público, Fundação Escola Superior do MPDFT, 2000/2001), Graduado em Direito (Universidade de Brasília, 1999). Pós-Doutor em Democracia e Direitos Humanos pelo Ius Gentium Conimbrigae (IGC) da Universidade de Coimbra (2018). Atualmente é Professor Titular do Programa de Mestrado e Doutorado em Direito do Centro Universitário de Brasília (UniCEUB) e dos cursos de especialização da FESMPDFT e da ESMPU. É professor do máster oficial universitário em Direitos Humanos, Interculturalidade e Desenvolvimento da Universidade Pablo de Olavide e Professor Investigador do Programa de Doutorado em Ciências Jurídicas e Políticas da mesma Universidade (linha: Direitos Humanos e Desenvolvimento). Promotor de Justiça do Ministério Público do Distrito Federal e Territórios.

2 Pesquisador do LAPIN - Laboratório de Pesquisa de Políticas Públicas em Internet, graduado em Direito pela Universidade de Brasília 
Justiça e Instituições Eficazes", da Agenda 2030 dos Objetivos de Desenvolvimento Sustentável (ODS) apresentado pelas Nações Unidas (ONU). Para atingir tal objetivo, o estudo delimita quais os agentes cuja produção normativa será analisada, para então realizar revisão bibliográfica sobre os conceitos de vítima, revisitando a literatura acadêmica e as fontes normativas que tratam deste conceito. Após isso, vem a minudenciar como se dá o papel do Direito dentro da construção das políticas públicas, entendendo a sua função e como se dá o ciclo de políticas públicas, além de explicar o Objetivo 16 da Agenda 2030 da ONU e qual a sua relação com as políticas públicas para as vítimas, além da delimitação temporal no que tange as normas prolatas pelos agentes aqui alvo do estudo. Feito isto, serão elencadas as normas que se adequarem aos parâmetros eleitos, com a explicação do seu conteúdo e características, para então entender o quanto houve de avanço no campo das políticas públicas das vítimas desde o início da vigência da Agenda 2030.

Palavras-chave

Vítima. Políticas Públicas. Agenda ODS 2030. Conselho Nacional de Justiça. Conselho Nacional do Ministério Público.

\section{Abstract}

This paper analyses que normative frame to public policies for the victim of crimes provided by actors of the criminal justice system. Then, it compares those policies with the $16^{\text {th }}$ Goal, named "Peace, justice and strong institutions", of the Sustainable Development Goals (SDS) presented by the United Nations. The paper defines which actors are going to be the subjects of the study, and then problematizes the concept of victim according to a literature review and an compilation of the international legal acts regarding the subject. It seeks to understand how public polices work and what's the role of Law in it, and explaining what is the $16^{\text {th }}$ Objective and its relation with public policies on behalf of victims of crime. After that, the norms that fit in the parameters fixed by the paper will be studied, explained and then scrutinized on how much the policies have advanced considering the $16^{\text {th }}$ Goal from the SDG United Nations' Agenda 2030.

Keywords

Crime Victim. Public Policies. Agenda SDS 2030. National Council of Justice. National Council of Prosecution Office. 


\section{INTRODUÇÃO}

A vítima foi relegada por muito tempo a uma posição secundária dentro do Direito: seja pela falta de interesse na vítima como objeto de estudo, seja pela na vítima como sujeito que sofre o delito, refletindo-se na inexistência de normas legais que versassem sobre como a vítima deveria ser tratada após a ocorrência do crime.

Tal negligência na elaboração de normas que tenham a vítima como sujeito central perdurou até o final do século XX, com a entrada na década de 1980 do Victims of Crime Act no âmbito da legislação federal nos Estados Unidos e a introdução da Convention on the Compensation of Victims of Violent Crimes em 1983 no âmbito europeu (FRADE, 2011, p. 82).

No âmbito internacional, foi editada a Resolução n. 40/34 de 1985, da ONU, que trouxe consigo a Declaração de Princípios Básicos de Justiça relativos às Vítimas da Criminalidade e Abuso de Poder (MOTA, 2012, p. 641), que apesar de não ser lei em sentido estrito, sendo apenas soft law, possuiu grande impacto no desenvolvimento como norte a ser seguido pelas legislações de cada país.

Neste contexto, a experiência brasileira visando um melhor trato da vítima dentro do ordenamento jurídico ganha maior tração com a introdução da Lei Maria da Penha em 2006 e a positivação do Programa Nacional de Segurança Pública com Cidadania - Pronasci, Lei 11.530/2007, que influenciou a 


\section{DELICTAE, Vol. 5, No8, Jan..-Jun. $2020 \mid 188$}

implementação das políticas públicas de proteção à vítima previstas na Lei Maria da Penha (CANÇADO, SUXBERGER, 2017, p. 41).

Com a vigência de tais diplomas, conjuntamente com a Lei 11.690/2008, que reformou o Código de Processo Penal, introduzindo uma série de direitos da vítima ao curso do processo, se destacando os direitos de proteção e informação, têm-se uma atualização da legislação visando a concretização de medidas em prol da vítima, tanto por meio de decisões judiciais, tanto pela construção de políticas públicas, possibilitando a expansão de um sistema de proteção às vítimas.

Cabe ressaltar esse caráter múltiplo do Direito, possibilitando a atuação de diferentes naturezas, pois o Direito passou por uma série de transformações, não possuindo mais um caráter que pode ser resumido em que uma norma "cuja execução é garantida por uma sanção externa e institucionalizada" (BOBBIO, 2011, p. 42), já que demonstra diversas facetas, entre as quais, a de servir como uma tecnologia de construção e operação de políticas públicas (COUTINHO, 2013, p. 193).

Para que se possa falar em um sistema de proteção à vítima dentro do direito pátrio, para além de uma norma que dita que a vítima deve ser respeitada e ter acessos a direitos, é necessário que existam medidas no sentido de sua concretização por meio de política governamental que garanta de fato a eficácia de tais direitos, pois o acesso ao direito deve ser entendido como 
um processo, sendo a positivação do direito apenas uma das etapas, não a última para a sua efetividade (SUXBERGER, 2018, p. 122).

O Poder Judiciário e o Ministério Público, por meio de seus órgãos nacionais (respectivamente, Conselho Nacional de Justiça e Conselho Nacional do Ministério Público), conformaram normativamente sua atuação em atenção às vítimas de crimes, com vistas a atender ao objetivo 16 dos Objetivos de Desenvolvimento Sustentável para 2030 das Nações Unidas? Essa é a hipótese que o presente artigo pretende verificar.

O foco do presente trabalho será a análise do direito entendido como essa tecnologia que viabiliza a operacionalização de políticas públicas visando concretizar as previsões normativas voltadas para a proteção das vítimas. Tal análise, que não comporta avaliação empírica de implementação dos atos normativos, não será capaz de indicar efetividade das políticas públicas, entendida esta como o impacto no problema público a que se dirige a ação estatal. No entanto, buscará problematizara construção dos marcos normativos que servem de base para a exteriorização das ações promovidas tanto pelo Poder Judiciário quanto pelo Ministério Público.

Como pano de fundo teórico, o artigo se vale da relação entre Direito e Políticas Públicas, especialmente as dimensões exercidas pelo Direito nessa relação. Ao se analisar o direito como tecnologia jurídica que possibilita a construção de 
política públicas, Coutinho divide o direito como tecnologia jurídica em quatro categorias: como objetivo, vocalizador de demandas, ferramenta e arranjo institucional (COUTINHO, 2013, p. 198), cada qual com características particulares, mas que ainda assim pode haver uma sobreposição entre uma categoria, pois tal categorização "não pode e não deve se esgotar em formulações genéricas, taxonômicas" (COUTINHO, 2013, p. 199), pois na sua dimensão empírica, o Direito se mostra mais complexo que a sua própria conceituação.

Para a realização de tal estudo, será feita a revisão bibliográfica dos conceitos de vítima, de direito e política pública, e utilizará de objeto de análise as previsões normativas criadas pelos atores atuantes no Judiciário, nomeadamente o Ministério Público e o Poder Judiciário, utilizando como representativos desses dois atores o Conselho Nacional do Ministério Público (CNMP) e o Conselho Nacional de Justiça (CNJ), pois centralizam a atuação institucional em nível nacional.

Por essa mesma razão é que não se analisará a atuação da Defensoria Pública, pois apesar de ser um ator importante do sistema de justiça brasileiro, não há um órgão nacional estatal institucionalizado nos mesmos moldes desses já referidos que unifique o posicionamento institucional e vise a construir uma política pública em âmbito nacional.

Não se ignora aqui a existência de coletivos nacionais, como o Colégio Nacional dos Defensores Públicos Gerais 
(CONDEGE), que, na ausência de um órgão normativamente institucionalizado, assume a representação da Defensoria Pública em âmbito nacional. No entanto, para a delimitação da presente investigação, busca-se a produção normativa realizada pelos agentes públicos estatais, normativamente institucionalizados, o que conduz à exclusão do CONDEGE e outros coletivos de abrangência nacional, como o Conselho Nacional dos Procuradores-Gerais (CNPG) existente no âmbito do Ministério Público brasileiro.

Também não irá se analisar o Ministério da Justiça, já que, a despeito da sua presença na construção de políticas públicas de segurança, com influência direta no funcionamento do Poder Judiciário, seu papel é ligado de forma direta ao Poder Executivo.

Como marco temporal, se utilizará o período do ano de 2015 até o final de 2019, diante da adoção da Agenda 2030 para o Desenvolvimento Sustentável pela ONU no ano de 2015, em especial do Objetivo 16, que visa a promoção do acesso à justiça e o fortalecimento de instituições, vendo quais medidas o CNJ e o CNMP já tomaram visando cumpri-lo.

Por fim, realizado o levantamento das previsões normativas expedidas pelo CNJ e pelo CNMP e sua análise para entender como está sendo feita a construção legal das políticas públicas de proteção à vítima, será realizado um cotejo com os referidos objetivos citados, para então determinar se já há um 
movimento das referidas instituições em seguir a cartilha da ONU.

\section{VÍTIMA: APROXIMAÇÃO CONCEITUAL}

Conforme já mencionado anteriormente, a vítima como objeto de estudo esteve ao largo do interesse da academia e da dogmática por um longo período de tempo, sem que se houvesse preocupação em desenvolver um conceito claro para o termo durante anos, sempre se entendendo que a vítima seria aquela que sofre o dano do delito de forma direta, um objeto dentro da relação processual penal que não possuiria grande importância (JORGE, 2002, p. 36).

A vítima foi redescoberta então na segunda metade do século XX, com a realização do Primeiro Simpósio Internacional sobre Vitimologia e com a fundação da Sociedade Mundial de Vitimologia na década de 1970 (MOTA, 2012, p. 633), sendo esta a terceira fase da evolução histórica dos estudos sobre a vítima como ciência (CANÇADO, SUXBERGER, 2017, p. 35).

Com o advento da Vitimologia, tem-se as primeiras tentativas de conceituação da palavra por parte da academia e dos ordenamentos jurídicos pelo mundo, com o foco na vítima como prioridade, tanto como objeto de estudo quanto como sujeito de direitos, há um alargamento do seu conceito, abarcando nuances que antes não tinham sido exploradas. 
Há um descolamento do conceito de vítima do conceito de "sujeito passivo do crime", entendido como o titular do bem jurídico violado pela conduta do sujeito ativo, pois tal conceito não conseguiria abarcar todos aqueles que sofreram algum tipo de dano pela ação delituosa.

Tal descolamento resta claro ao se analisar o conceito trazido por Antonio Scarance, que alarga a tal ponto o conceito de vítima que passa inclusive do âmbito do direito penal, trazendo para dentro do conceito também vítimas de atos ilícitos civis, acidentes de trabalho, entre outros (JORGE, 2002, p. 36). Como também consequência deste alargamento, no que tange a Vitimologia, não é possível traçar um único conceito de vítima, havendo uma multiplicidade de definições, além da falta de coincidência entre o conceito utilizado pelo Direito Penal e para a Vitimologia (MOTA, 2012, p. 642).

Cabe ressaltar que o ordenamento jurídico pátrio não dá uma definição do que seria a vítima, a despeito de existirem dispositivos que versem sobre direitos da vítima dentro do Código de Processo Penal, tais como a ação civil ex delicto prevista nos artigos 63 e 64 do referido Código, por exemplo.

Existem projetos de lei visando a criação de um Estatuto da Vítima, tais como o Projeto de Lei 3503/2004 e o Projeto de Lei do Senado 65/2016, que trazem definições legais do que seria uma vítima para o direito brasileiro, contudo, não há nenhum dispositivo vigente que conceitue o termo. 
É necessário então que haja a eleição de um conceito que venha a guiar a análise que será realizada dos normas que foram produzidas pelos agentes governamentais visando a proteção das vítimas. Diante disto, e tendo em vista que a Agenda 2030 da ONU será o objeto que servirá de marco para ver o quanto de avanço houve na questão da proteção das vítimas, será utilizado o conceito criado pela Declaração dos Princípios Fundamentais de Justiça relativos às Vítimas da Criminalidade e de Abuso de Poder, adotada pela Assembleia-Geral da Organização das Nações Unidas (ONU), por sua Resolução no 40/34 de 29 de novembro de 1985. Nela, vítima é conceituada da seguinte forma:

A. Vitimas da criminalidade

1. Entendem-se por "vítimas" as pessoas que, individual ou coletivamente tenham sofrido um prejuízo, nomeadamente um atentado à sua integridade física e um sofrimento de ordem moral, uma perda material, ou um grave atentado aos seus direitos fundamentais, como consequência de atos ou de omissões violadores das leis vigor num Estado membro, incluindo as que proíbem o abuso de poder.

2. Uma pessoa pode ser considerada como "vitima", no quadro da Declaração, quer o 
autor seja ou não identificado, preso, processado ou declarado culpado, e qualquer que sejam os laços de parentesco deste com a vítima. O termo vítima, inclui, conforme o caso, a família próxima ou as pessoas a cargo da vítima e as pessoas que tenham sofrido um prejuízo ao intervirem para prestar assistência ás vítimas em situação de carência ou para impedir a vitimização. (ORGANIZAÇÃO DAS NAÇÕES UNIDAS, 1985).

É possível verificar que o conceito de vítima penal ultrapassa aquele que sofre o dano direto pelo direto, abarcando também familiares e pessoas próximas que tenham sofrido algum tipo de dano ao se relacionarem com o delito, mesmo que em momento posterior.

Tal definição possibilita que haja uma abertura para uma abordagem mais completa dos efeitos do delito, pois os efeitos do crime não se encerram em si, possuindo efeitos reflexos, sendo tal natureza reconhecida até mesmo pelo ordenamento pátrio ao incluir a circunstância "consequências do crime" na análise de primeira fase da dosimetria prevista no art. 59 do Código Penal.

A aproximação conceitual de vítima ora indicada não se refere às minorias, que podem ser consideradas como aquelas 
resultantes de opressões sistêmicas, de macroestruturas sociais cujo funcionamento acaba por impedir o acesso a direitos a um certo grupo ligado por elos raciais, sociais, étnicos-culturais, políticos, entre outros, mas assim aquelas vítimas de crimes penais, que se enquadram como vulneráveis.

A vulnerabilidade, diferentemente das características das minorias, são características que devem ser mitigadas, ou mesmo enfrentadas,pelas políticas públicas e pelo Direito com um todo. Há uma aproximação entre os dois grupos na medida que lhe são negados direitos, contudo as políticas públicas de ambas possuem diferenças marcantes (BRITO, 2009, p.107) de ajuda de minorias possuem um viés marcado pelo respeito das características que singularizam aquele grupo minoritário, enquanto as políticas públicas voltadas para vulneráveis buscam erradicar as características que os tornam mais suscetíveis de terem seus direitos violados ou que agravem a situação após a violação.

A partir dessa conceituação da vítima de crime como grupo vulnerável, há de se falar da natureza dos direitos das vítimas: eles tendem a serem divididos em quatro categorias, nomeadamente direito à proteção, à informação, à participação e à solução consensual do processo (CANÇADO, SUXBERGER, 2017, p. 38).

Para os fins do presente trabalho, serão analisadas as disposições que versam sobre todas as vertentes citadas, pois não 
há restrição realizada pelo Objetivo 16 da Agenda 2030 da Organização das Nações Unidas (ONU) na promoção dos direitos das vítimas.

\section{O DIREITO COMO TECNOLOGIA PARA POLÍTICAS PÚBLICAS}

Para o presente trabalho, mais importante que uma definição clara do que seria uma política pública para a literatura acadêmica, o que se mostra complexo em vista da miríade de definições que existem sobre o termo (CANÇADO, SUXBERGER, 2017, p. 42), interessa aqui entender em que ponto da elaboração da política pública o direito aparece e qual o papel do direito na construção da política pública.

No que tange a função do direito nas políticas públicas, ele aparece como tecnologia jurídica, se mostrando como "a visualização dos arranjos, dos sujeitos, dos instrumentos próprios de realização do direito" (CANÇADO, SUXBERGER, 2017, p. 113). Embora a institucionalização seja condição necessária, mas não por si só suficiente à implementação do Direito, ela é autorizativa da compreensão de que, a partir dela, o sistema oferece respostas previsíveis, seguras e reiteráveis.

É dizer: a institucionalização assegura que o sistema jurídico se renove por meio de procedimentos estabelecidos e que essa formalização da atuação estatal ocorra justamente em observância a regras previamente ajustadas. (CALSAMIGLIA 
BLANCAFORT, 1994, p. 749) Dentro desta faceta, o direito como tecnologia jurídica assegura a concretização dos direitos prescritos, viabilizando a exteriorização da ação estatal que conforma as políticas públicas (SUXBERGER, 2018, p. 121) ao assegurar uma estrutura normativa que servirá de guia para o agir do agente que promover a concretização da política pública.

Diante disto, é possível afirmar que o Direito se cumpre quando, para além da criação de marcos normativos que prescrevem direitos e deveres, mas também na viabilização da concreção destes direitos com a construção de políticas públicas para que haja uma real efetividade do que preceitua, sob pena de se mostrar ineficaz como instrumento de alteração da realidade, pois, para além de uma "teorização abstrata e teórica de seus problemas, é crucial compreender que ele também materializa função igualmente importante de instrumentalização de suas prescrições" (SUXBERGER, 2018. p. 113).

Ao expandir tal conceito ao analisar o papel do direito nas políticas públicas, Coutinho vem a dividir o direito como tecnologia jurídica em quatro categorias: como objetivo, vocalizador de demandas, ferramenta e arranjo institucional (COUTINHO, 2013 p. 194). Não se trabalhará no direito como vocalizador de demandas, pois essa dimensão de accountability é um passo posterior ao que o trabalho se propõe a analisar.

O Direito como objetivo se realiza ao determinar quais são os objetivos concretos a serem perseguidos pelas políticas 
públicas, determinando o ponto final que a realidade deve atingir, formalizando metas a serem atingidas.

Em sua dimensão instrumental, o Direito poderia ser conceituado como "uma caixa de ferramentas, que executa tarefas-meio conectadas a certos fins de forma mais ou menos eficaz, sendo o grau de eficácia, em parte, dependente da adequação do meio escolhido" (COUTINHO, 2013, p. 197). O que se analisa aqui é como o direito pode funcionar como um instrumento visando a implementação das políticas públicas.

Já na dimensão estruturante, isto é, de arranjo institucional, se tenta responder as seguintes questões: quem faz o que? Com que competências? Como se dá a articulação de uma política pública em questão com as demais existentes. Aqui, o direito visa a dividir competências, coordena relações entre os entes que participam da construção da política pública, definindo tarefas entre eles (COUTINHO, 2013, p. 198).

Logo, o que se busca aqui é entender como o Direito foi utilizado pelos atores eleitos como alvo da pesquisa ao estruturarem as políticas públicas, vendo como foi realizada a divisão de tarefas e como o próprio direito foi instrumentalizado para viabilizar a implementação das políticas públicas de proteção às vítimas penais.

Entender como tais dimensões do direito como tecnologia jurídica aparecem dentro as normas a serem analisadas se mostra necessário para que se possa fazer um juízo sobre a 
atuação estatal na concretização das políticas públicas: o Brasil possui uma tendência a não cumprir com suas políticas públicas, sendo várias as razões apontadas para tal, cujo debate não será realizado, contudo, o direito como objetivo possui uma proximidade com o direito que prescreve direitos e deveres fora das políticas públicas, sem trazer o modo da concretização desses direitos, e uma maior quantidade de normas com esse caráter pode indicar que há apenas na fixação dos objetivos sem que se preocupe em como torna-los realidade.

Acerca do chamado "ciclo de política pública", que é o processo de elaboração propriamente dito, é possível se falar na existência de sete fases, consistindo na "identificação do problema, formação da agenda, formulação de alternativas, tomada de decisão, implementação, avaliação e extinção" (CANÇADO, SUXBERGER, 2017, p. 42).

Como já destacado, o presente trabalho não avalia empiricamente os efeitos ou impactos das políticas públicas implementadas pelo Ministério Público e pelo Judiciário. Não se estuda a implementação, avaliação e extinção, mas sim sobre como se deu a formação da política pública em si, por meio da positivação dos objetivos estabelecidos pelo Direito a partir da expedição de normas que delimitam como a ação estatal desses atores deve ser exteriorizada.

Utilizando-se da categorização feita por Randall B. Ripley, o produto da fase de formulação e legitimação dos 
objetivos e dos programas traçados, na qual há a eleição de metas e a estruturação básica de como será construída a política pública, resulta em normas que refletem o posicionamento tomado pelos entes, para que então se passe para uma fase de implementação (RIPLEY, 1995, p. 148).

Realizado tal passo, passa-se à comparação com o Objetivo 16 trazido pela Agenda dos Objetivos de Desenvolvimento Sustentável das Nações Unidas para 2030, de modo a se indicar o quanto de avanço se tem no campo da criação das normas que estruturam a política pública.

O Objetivo 16 da ONU é subdivido em subitens, nomeadamente:

Objetivo 16. Promover sociedades pacíficas e inclusivas para o desenvolvimento sustentável, proporcionar o acesso à justiça para todos e construir instituições eficazes, responsáveis e inclusivas em todos os níveis 16.1 Reduzir significativamente todas as formas de violência $e$ as taxas de mortalidade relacionada em todos os lugares

16.2 Acabar com abuso, exploração, tráfico e todas as formas de violência e tortura contra crianças 
16.3 Promover o Estado de Direito, em nível nacional e internacional, e garantir a igualdade de acesso à justiça para todos 16.4 Até 2030, reduzir significativamente os fluxos financeiros e de armas ilegais, reforçar a recuperação e devolução de recursos roubados e combater todas as formas de crime organizado

16.5 Reduzir substancialmente a corrupção e o suborno em todas as suas formas 16.6 Desenvolver instituições eficazes, responsáveis e transparentes em todos os níveis

16.7 Garantir a tomada de decisão responsiva, inclusiva, participativa e representativa em todos os níveis

16.8 Ampliar e fortalecer a participação dos países em desenvolvimento nas instituições de governança global

16.9 Até 2030, fornecer identidade legal para todos, incluindo o registro de nascimento

16.10 Assegurar o acesso público à informação e proteger as liberdades fundamentais, em conformidade com a 
legislação nacional e os acordos internacionais

16.a Fortalecer as instituições nacionais relevantes, inclusive por meio da cooperação internacional, para a construção de capacidades em todos os níveis, em particular nos países em desenvolvimento, para a prevenção da violência e o combate ao terrorismo e ao crime

16.b Promover e fazer cumprir leis e políticas não discriminatórias para $\mathrm{o}$ desenvolvimento sustentável

Dentro desses subitens, os Objetivos 16.1, 16.2, 16.3, que possuem relação com a construção de políticas públicas de proteção de vítimas de crimes, em face que os indicadores que foram criados para aferir o seu cumprimento levam em conta a existência de vítimas. São eles:

Meta 16.1: Reduzir significativamente todas as formas de violência e as taxas de mortalidade relacionada em todos os lugares

Indicador 16.1.1: Número de vítimas de homicídio doloso por 100,000 pessoas, de acordo com sexo e idade (...) 
Indicador 16.1.3: Proporção da população sujeita a (a) violência física, (b) violência psicológica e (c) violência sexual nos últimos 12 meses

(...)

Meta 16.2: Acabar com abuso, exploração, tráfico e todas as formas de violência e tortura contra crianças

(...)

Indicador 16.2.2: Número de vítimas de tráfico de pessoas por 100,000 pessoas, de acordo com sexo, idade e forma de exploração

Indicador 16.2.3: Proporção de mulheres jovens e homens de idade entre 18-29 anos que sofreram à violência sexual até os 18 anos de idade

Meta 16.3: Promover o Estado de Direito, em nível nacional e internacional, e garantir a igualdade de acesso à justiça para todos

Indicador 16.3.1: Proporção de vítimas de violência nos últimos 12 meses que denunciaram serem vítimas para as autoridades competentes ou se utilizaram 
de outros meios de resolução de conflitos oficialmente reconhecidos

(...)

Tomando-se os objetivos das Nações Unidas como parâmetro a ser observado para instituições eficazes, será possível determinar se houve avanço da agenda de proteção às vítimas por parte do CNMP e do CNJ na qualidade de atores de políticas públicas voltadas às vítimas pelo Judiciário e pelo Ministério Público respectivamente.

\section{PRODUÇÃO NORAMATIVA DO CNMP E CNJ PARA POLÍTICAS PÚBLICAS DE PROTEÇÃO À VÍTIMA}

Delimitado o objeto de estudo, passa-se à análise das normas expedidas pelo CNMP e pelo CNJ que visam construir as políticas públicas de proteção à vítima. Para fins de clareza, a análise será dividida de acordo com a autoria da norma, pois, como cada agente possui um âmbito de competência bem definido, delimitada por normas constitucionais, respectivamente os artigos 130-A e 103-B da Constituição Federal.

No âmbito do Poder Judiciário, representado pelo Conselho Nacional de Justiça, temos como marco normativo a Resolução 253/2018. Tal resolução centraliza todo o tema acerca das vítimas de crimes e as políticas públicas relacionadas.

A própria resolução reconhece o papel central da Declaração dos Princípios Fundamentais de Justiça relativos às 
Vítimas da Criminalidade e de Abuso de Poder ao citá-la de forma direta, além de reconhecer a omissão do ordenamento jurídico em definir o que é vítima, que não poderia impedir a criação de uma política pública voltada para a vítima, sendo papel do Poder Judiciário buscar alguma solução.

A resolução se utiliza de um conceito de vítima menos amplo do que a da Resolução 40/34, pois afasta as pessoas que tenham sofrido um prejuízo ao intervirem para prestar assistência ás vítimas em situação de carência ou para impedir a vitimização:

Art. 1 (...)

§1ํ Para os fins da presente Resolução, consideram-se vítimas as pessoas que tenham sofrido dano físico, material, patrimonial ou psicológico em razão de crime ou ato infracional cometido por terceiro, ainda que não identificado, julgado ou condenado.

§2o O disposto na presente Resolução aplica-se igualmente aos cônjuges, companheiros, familiares em linha reta, irmãos e dependentes da vítima cuja lesão tenha sido causada por um crime.

Acerca do conteúdo da Resolução, há previsões abarcando todas as vertentes dos direitos das vítimas: há uma 
maior ênfase no direito de informação, conforme art. 3o e seus incisos, o artigo 5o, que visa dar cumprimento aos direitos de informação já previstos no Código de Processo Penal, tratando também do direito de proteção e participação de forma mais rápida, além do artigo 7o, que facilita o acesso das vítimas aos autos dos processos.

Contudo, há menções aos outros direitos das vítimas de forma mais esparsa: o art. 5o, inciso I traz norma que visa a concretização do direito à participação pela vítima, o direito à solução consensual do processo no art. 3o, inciso VI, nos moldes da Resolução 225/16, e direitos de proteção ao citar a necessidade de encaminhamento das vítimas aos programas de proteção a vítima ameaçadas no inciso $\mathrm{V}$ do mesmo artigo.

Há uma predominância do direito como objetivo e como arranjo institucional. Exemplo do primeiro é o artigo 3o, inciso I, que prescreve o patamar de atendimento que deve ser dado às vítimas, e representativo do seu é a determinação do art. 8o para a Corregedoria Nacional de Justiça para fiscalizar o cumprimento do art. 201, parágrafo 2o do Código de Processo Penal, dividindo competências. Há uma menor ocorrência do direito como ferramenta, o que parece acontecer em face da predominância da faceta do direito como objeto na Resolução.

Já mencionada, também há a Resolução 225/16, que prevê a instauração da justiça restaurativa dentro do Judiciário. Diferentemente da Resolução 253/2018, aqui há uma maior 
predominância do direito como arranjo institucional, em vista que a resolução busca basicamente traçar as competências de cada agente participante, demonstrado claramente nos Capítulos II e III da Resolução.

Ela vem a definir que seria a justiça restaurativa no seu art. 1ำ, reflexo direto do direito à solução consensual do processo, dando foco na participação da vítima, família e envolvidos e da comunidade atingida pelo fato, conforme inciso I do referido artigo, podendo ser utilizada de forma alternativa ou concorrente com o processo convencional, diante da previsão do §2. No artigo 2o vem a definir os princípios que irão reger a aplicação da justiça restaurativa e o modo como o procedimento irá se desenvolver.

Do artigo 3o em diante há a estruturação do modo como a Justiça Restaurativa irá funcionar, colocando objetivos, dividindo competências entre os entes participantes do sistema de justiça restaurativa e os tribunais no art. 4o e 5o, respectivamente. No Capítulo VI, que abarca o artigo 7o ao 12, há a descrição do procedimento no âmbito judicial. Relativamente a políticas públicas, o Capítulo VII cria os mecanismos de monitoramento e avaliação do projeto de instauração da Justiça Restaurativa.

Ao longo de toda a Resolução, há uma grande preocupação com a busca por tentar estruturar a política pública de implantação da justiça restaurativa, com uma preocupação 
com a sua concretização. $O$ direto como objetivo aparece de forma paralela em alguns artigos, como o artigo 3o, mas fica claro que o objetivo principal da Resolução é realmente

Por últimos, temos a Resolução 299/19, que traz dispositivos que versam sobre o sistema de garantia das crianças e adolescentes vítimas ou testemunhas de violência. A preocupação da resolução é garantir o direito a participação dessas vítimas conforme as peculiaridades existentes, buscando a implementação ao depoimento especial previsto pela Lei 13.431/17.

Para tal, a Resolução traz normas estruturantes sobre a política pública, possibilitando a utilização de instrumentos legais tais como convênios entre entes estatais, previsto no Capítulo II, além do modo como o depoimento deve ocorrer, prevendo a necessidade de instalação de salas especiais e a criação de equipes voltadas apenas para a realização do depoimento especial, com a capacitação dos magistrados e servidores nos capítulos IV e V, sendo ressaltada a necessidade de se cumprir o procedimento conforme previsto na Lei $13.431 / 17$ no Capítulo VI, explicitando como ele deve ser conduzido.

Aqui pode se ver uma predominância do direito como ferramenta e como arranjo institucional, visualizado com as previsões orçamentárias no art. $14, \S^{1}$, por exemplo e a montagem de convênios entre os órgãos estatais para a viabilização da política pública, além dos mecanismos de controle 
da política pública, sem que haja o protagonismo do direito como objetivo em vista da já existente de legislação que prevê o depoimento especial e de outros diplomas normativos que explicitam a necessidade de se dar um maior foco nas vítimas crianças e adolescentes.

No âmbito do CNMP, a despeito da posição que o órgão possui em frente aos Ministérios Públicos Estaduais e da União, não há uma conformação normativa sobre o assunto tal como a realizada pelo CNJ no Judiciário.

Tal situação é verificável pela falta de normas que versam sobre a vítima como categoria separada. O que existem são normas esparsas que tratam do tema de modo mais pontual, com um tipo de vítima em específico.

Exemplo disto é a Nota Técnica 11/2016 do CNMP, que versa sobre a atuação do Ministério Público dentro das audiências de custódia que tratam de violência contra a mulher. Ela traz previsões visando a concretização dos direitos da vítima nas suas quatro vertentes, com maior grau de abstração, como no ponto (g), que traz a necessidade da atuação efetiva do Ministério Público nesta seara até medidas mais concretas, como o meio como se deve dar o cumprimento do art. 21 da Lei 11.340/06, concretizando o direito à informação, utilizando do direito como ferramenta.

Também há de ser citada a Resolução 118/2014, que no seu artigo 13 e 14 trata da aplicação das práticas de justiça 
restaurativa, mas traz de modo mais abstrato, na dimensão do direito como objetivo, sem fazer qualquer outro tipo de previsão sobre a sua aplicação.

Por fim, deve ser citado o Guia Prático de Atuação do Ministério Público na Proteção e Amparo às Vítimas de Criminalidade, que buscou agregar as iniciativas e práticas do Ministério Público sobre o tema, estabelecendo diretivas na atuação da instituição ao lidar com as vítimas de delitos. A predominância aqui é do direito como objetivo, sem as outras dimensões do direito como tecnologia jurídica aparecendo, e o Guia não possui caráter de Resolução, ou seja, não possui força normativa alguma.

Influenciados pelo Estatuto da Vítima de Portugal e da Espanha, além da Resolução no 40/30 e do Projeto de Lei do Senado Federal no 65/2016, divide o conceito de vítima em 3 categorias: a vítima direta, aquela que sofreu lesão direta causada pela ação ou omissão do agente, a vítima indireta, os parentes de pessoa cuja morte ou desaparecimento tenha sido diretamente causada por um delito ou ato infracional e que tenham sofrido dano em consequência da morte e desaparecimento dessa pessoa e os familiares da vítima e pessoas economicamente dependentes da vítima.

Foi criada a categoria "vítimas especialmente vulneráveis", abarcando aqueles que possuiriam uma fragilidade maior em decorrência da idade, do estado de saúde ou deficiência 
ou das sequelas psicológicas decorrentes do crime, o que devem receber maior atenção em vista desta vulnerabilidade exacerbada.

Além disto, tem a sugestão de criação de Núcleos ou Centros de Atendimentos à Vítimas, com a parceria de atendimento externa pública e privada, a necessidade de aplicação de direitos de informação e de proteção à vítima já prescritos em lei, o enfrentamento aos processos de vitimização secundária e o uso da justiça restaurativa. Contudo, em tal documento há a fixação de diretrizes, sem indicar como se deve concretiza-las, a despeito de citar as iniciativas de Ministérios Públicos Estaduais e da União.

\section{CONSIDERAÇÕES FINAIS}

Diante das normas trazidas anteriormente, é possível traçar algumas conclusões a partir da problematização eleita. Respondendo ao questionamento dirigido à conformação normativa promovida pelo CNJ e pelo CNMP para políticas públicas de atenção às vítimas de crimes, reconhece-se um maior protagonismo do Poder Judiciário na construção das políticas públicas de proteção à vítima, inclusive com a fixação de um marco normativo que define termos centrais para a implementação da política pública, tal como o que seria a vítima.

Outra característica que pode ser levantada a favor dessa conclusão refere-se à existência de normas que visam estruturar a política pública, com o protagonismo estruturante do 
Direito como arranjo institucional e do Direito instrumentalmente como ferramenta. Vê-se, na edição desses diplomas normativos, uma preocupação de concretização, para além de uma sinalização da necessidade da criação da política pública de forma abstrata.

Neste sentido, a Resolução 299/19 ilustra bem este ponto, pois ela se preocupa com questões de competência, a utilização dos meios jurídicos possíveis para a construção de acordos, entre outras questões.

No âmbito do Ministério Público, fica clara a falta de estruturação normativa visando a construção das políticas públicas voltadas à vítima, pois sequer há a definição em Resolução do que seria a vítima. É possível argumentar que há uma tentativa de viabilização dessas políticas públicas, vide a Nota Técnica 11 citada anteriormente, mas não há a expedição de normas regulamentadoras pelo CNMP dando racionalidade e uma estrutura normativa para a adoção de uma futura política pública.

O Guia Prático de Atuação do Ministério Público na Proteção e Amparo às Vítimas de Criminalidade, a despeito da sua importância prática, ao reunir uma série de conceitos e formalizar diversas sugestões pertinentes para a atuação da instituição, não possui caráter cogente, pois não é Resolução, sem poder para determinar a atuação com força vinculante, o que impede que se entenda que possua o mesmo peso que a Resolução 
CNJ 253/18 na presente análise. Além disso, há um caráter de Direito como objetivo presente ao longo de todo o Guia, mas carente de sua dimensão instrumental, pois não há previsão de como se deveriam dividir competências ou quais os meios jurídicos a fim de viabilizar políticas públicas de proteção à vítima. Na ausência dessa previsão, deixa-se a cargo dos diversos Ministérios Públicos a melhor maneira de conformação desses objetivos.

A construção de um marco fixo, com a definição de vítima e outros pontos como a divisão de competências dentro da instituição talvez esteja sendo obstruído pela espera à aprovação do Projeto de Lei do Senado Federal 65/2016, que é citado diversas vezes pelo Guia Prático do Ministério Público, o que demonstra um interesse da instituição com o referido projeto de lei.

Por fim, comparando com o Objetivo 16 da Agenda 2030 da ONU, é possível concluir que há um avanço no sentido de concretizar os objetivos prescritos no Objetivo 16, com a construção de políticas públicas pelo Poder Judiciário, sendo a atuação do Ministério Público mais tímida, contudo, já há uma busca por tentar racionalizar o assunto e ver qual seria o panorama fático com que estão lidando. Exemplo disto uma preocupação direta tanto do CNMP quanto do CNJ na questão relativa à vitimização secundária, visto no Guia Prático feito pelo 
CNMP e no art. 2o da Resolução no 253/18, um avanço claro de acordo com o Indicador 16.3.1.

Não há dúvidas que é necessário avançar na promoção da agenda de proteção das vítimas, mas pode-se afirmar que houve já uma movimentação de ambos agentes estatal visando a instituição e melhora das políticas públicas voltadas para as vítimas. A aprovação do Projeto de Lei do Senado 65/2016 tornará o cumprimento de tal objetivo mais rápido, pois criará o marco normativo que poderá ser utilizado de base para a concretização das referidas políticas públicas.

\section{REFERÊNCIAS}

ASSEMBLÉIA GERAL DAS NAÇÕES UNIDAS. Declaração dos Princípios Básicos de Justiça Relativos às Vítimas da Criminalidade e de Abuso de Poder. Resolução no 40/30, de 29 de Novembro de 1985, 1985. Disponivel em: https://www2.camara.leg.br/atividadelegislativa/comissoes/comissoes-permanentes/cdhm/comitebrasileiro-de-direitos-humanos-e-politica-

externa/DecPrincBasJustVitCriAbuPod.html. Acesso em: 22 Dezembro 2019.

CALSAMIGLIA BLANCAFORT, A. Sobre la Dogmática Jurídica: presupoestos y funciones del saber jurídico. Anales de la Catedra Francisco Suárez, n. 22, p. 235-276, 1982. ISSN 0008-7750. 
BOBBIO, N. Teoria do Ordenamento Jurídico. 1a. ed. São Paulo: EDIPRO, 2011.

BRASIL. DECRETO-LEI No 2.848, DE 7 DE DEZEMBRO DE 1940. Código Penal, 1940. Disponivel em: http://www.planalto.gov.br/ccivil_03/decretolei/del2848compilado.htm. Acesso em: 19 Dezembro 2019. BRASIL. DECRETO-LEI № 3.689, DE 3 DE OUTUBRO DE 1941. Código de Processo Penal, 1941. Disponivel em: http://www.planalto.gov.br/ccivil_03/decreto-lei/del3689.htm. Acesso em: 19 Dezembro 2019.

BRITO, J. D. Minorias e grupos vulneráveis: aquilatando as possíveis diferenças para os fins de implementação das políticas públicas. Revista do Programa de Mestrado em Ciência Jurídica da Fundinopi, Jacarezinho, v. 1, n. 11, p. 95-110, Março 2009. ISSN 1676-2800.

CALFURRAPA, R. B. Víctima, reparación y proceso penal: una proyección desde las teorías expresivas de la pena. Revista Brasileira de Direito Processual Penal, Porto Alegre, v. 5, n. 1, p. 145-190, jan./abr 2019.

CALSAMIGLIA BLANCAFORT, A. Geografía de las normas de competencia. Doxa: cuadernos de filosofía del derecho, Alicante, v. 2, n. 16, p. 747-768, 1994. ISSN 0214-8676.

CÂMARA DOS DEPUTADOS. Define os direitos das vítimas de ações criminosas e regulamenta o art. 245 da Constituição Federal, para criar o Fundo Nacional de Assistência às Vítimas de 
Crimes Violentos (Funav), além de outras providências. Projeto de Lei 3503/2004, 2003. Disponivel em: https:/www.camara.leg.br/proposicoesWeb/fichadetramitacao? idProposicao=252323. Acesso em: 22 Dezembro 2019.

CONSELHO NACIONAL DE JUSTIÇA. Dispõe sobre a Política Nacional de Justiça Restaurativa no âmbito do Poder Judiciário e dá outras providências. Resolução 225, de 31 de maio de 2016, 2016. Disponivel em: https://atos.cnj.jus.br/atos/detalhar/2289. Acesso em: 22 Dezembro 2019.

CONSELHO NACIONAL DE JUSTIÇA. Define a política institucional do Poder Judiciário de atenção e apoio às vítimas de crimes e atos infracionais. Resolução 253, de 04 de setembro de 2018, 2018. Disponivel em: https://atos.cnj.jus.br/atos/detalhar/2668. Acesso em: 22 Dezembro 2019.

CONSELHO NACIONAL DE JUSTIÇA. Dispõe sobre o sistema de garantia de direitos da criança e do adolescente vítima ou testemunha de violência, de que trata a Lei no 13.431, de 4 de abril de 2017. Resolução no 299, de 05 de novembro de 2019, 2019.

Disponivel

em: https://atos.cnj.jus.br/files/original000346201912045de6f7e29dc d6.pdf. Acesso em: 22 Dezembro 2019.

CONSELHO NACIONAL DO MINISTÉRIO PÚBLICO. Dispõe sobre a Politica Nacional de Incentivo à Autocomposição no âmbito do Ministério Públicos e dá outras providências. 
Resolução no 118, de 1o de dezembro de 2014, 2014. Disponivel em:

https:/www.cnmp.mp.br/portal/images/Resolucoes/Resolu\%C3 \%A7\%C3\%A3o-118.pdf. Acesso em: 22 dezembro 2019.

CONSELHO NACIONAL DO MINISTÉRIO PÚBLICO. Nota Técnica do Conselho Nacional do Ministério Público sobre a atuação do Ministério Público nas Audiências de Custódia em casos de Violência Doméstica e Familiar contra a Mulher. Nota Técnica no11, de 27 de Julho de 2016, 2016. Disponivel em: https:/www.cnmp.mp.br/portal/images/Normas/Notas_Tecnica s/NOTA_TCNICA_11.pdf. Acesso em: 22 dezembro 2019.

CONSELHO NACIONAL DO MINISTÉRIO PÚBLICO. Guia prático de atuação do Ministério Público na proteção e amparo às vítimas de criminalidade. Conselho Nacional do Ministério Público. Brasília, p. 40. 2019.

COUTINHO, D. O direito nas políticas públicas. In: MARQUES, E. A política pública como campo disciplinar. São Paulo: Unesp, 2013. p. 181-200.

CRUZ, A. C. et al. A reparação à vítima do delito como terceira via. Revista Eletrônia da Fainor, Vitória da Conquista, v. 8, n. 1, p. 3-19, jan./jun. 2015.

FRADE, E. V. D. A. Os direitos da vítima da criminalidade. Porto Alegre: Universidade Federal do Rio Grande do Sul, 2011.

FREIRE, C. M. C. D. B. P. Medidas alternativas ao processo penal: a mediação como meio extrajudicial de gerenciamento de 
conflitos penais na fase pré-processual. Revista Justiça do Direito, v. 32, n. 3, p. 642-670, set./dez. 2018.

JORGE, A. P. Em busca da satisfação dos interesses da vítima penal. Recife: Universidade de Pernambuco, 2002.

JUNCKER, J.-C. Strenghtening victims' rights: from compensation to reparation. União Europeia. [S.l.], p. 63. 2019. (978-92-76-01401-0).

JÚNIOR, A. B. F. O combate à impunidade como direito fundamental da vítima e da sociedade. Revista Jurídica ESMP, São Paulo, v. 14, p. 149-162, 2018.

KUWAHARA, S. Dilemas do Programa de Proteção a Vítimas e Testemunhas Ameaçadas no Brasil. Política criminal, v. 11, n. 22, p. 439-466, Dezembro 2016.

MORAIS, F. D. M. B. B. D.; NETO, J. A.; SOARES, Y. F. A justiça restaurativa como mecanismo de horizontalização de conflitos penais e de reconhecimento das vítimas como sujeito de direitos. Revista Brasileira de Direito Processual Penal, Porto Alegre, v. 5, n. 1, p. 191-218, jan./abr. 2019.

MOTA, I. L. Breves linhas sobre vitimologia, redescobrimento da vítima e suas várias faces: algumas questões relevantes. Revista Jurídica da Presidência, Brasília, v. 13, n. 101, p. 629-655, Janeiro 2012.

OLIVEIRA, A. D.; PALODETTO, A. K. T. Vitimologia e a sua relação com a criminologia. Ponto de Vista Jurídico, Caçador, v. 2, n. 2, p. 68-80, jul./ago. 2013. 
ORGANIZAÇÃO DAS NAÇÕES UNIDAS. Objetivo 16, 2016. Disponivel em: https:/nacoesunidas.org/pos2015/ods16/. Acesso em: 22 Dezembro 2019.

ORGANIZAÇÃO DAS NAÇÕES UNIDAS. Resolution adopted by the General Assembly on Work of the Statistical Commission pertaining to the 2030 Agenda for Sustainable Development. SDG Indicators, 2017. Disponivel em:https://undocs.org/A/RES/71/313. Acesso em: 22 Dezembro 2019.

PAIVA, W. P. D. S.; NETO, C. E. D. S. Reparação do dano como terceira via de punibilidade. Revista Jurídica da UFERSA, Mossoró, v. 1, n. 2, p. 119-134, ago./dez. 2017. ISSN 2526-9488. RIBOLI, E. B. Um "tribunal orientado para a vítima": o minimalismo de Nils Christie e as suas contribuições à justiça restaurativa. Revista Brasileira de Direito Processual Penal, Porto Alegre, v. 5, n. 1, p. 253-298, abril 2019.

RIPLEY, R. B. Stages of the Policy Process. In: MCCOOL, D. C. Public Policy Theories, Models and Concepts: An Anthology. Chicago: Prentice-Hall, 1995. p. 48-55.

SENADO FEDERAL. Cria o Ato Nacional dos Direitos das Vítimas de Crimes e altera o Decreto-Lei no 3.689, de 3 de outubro de 1941 (Código de Processo Penal).. Projeto de Lei do Senado $\mathrm{n}^{\circ}$ 65, de 2016, 2016. Disponivel em: https:/www25.senado.leg.br/web/atividade/materias//materia/125010. Acesso em: 22 Dezembro 2019. 
SUXBERG, A. H. G. O Direito nas Políticas Públicas: o Déficit de Efetividade dos Direitos é um Problema Normativo ou Institucional? In: __ Direitos Humanos e Democracia: estudos em homenagem ao Professor Vital Moreira. Rio de Janeiro: Lumen Juris, 2018. p. 111-127.

SUXBERGER, A. H. G.; CANÇADO, M. L. Políticas públicas de proteção à vítima: uma proposta de arranjo institucional de segurança pública. Opinião Jurídica, Fortaleza, n. 20, p. 32-58, Janeiro 2017.

VIEIRA, P. M. A Vítima enquanto sujeito processual e à luz das recentes alterações legislativas. In: __ Julgar. 28. ed. Coimbra: Coimbra Editora, 2016. p. 171-209. 